\title{
A simple PCR-based approach for rapid detection of Ips typographus and Ips duplicatus in the presence of (associated) symbionts and parasites
}

\author{
Matthias Becker ${ }^{1} \cdot$ Stephan König ${ }^{1} \cdot$ Björn Hoppe ${ }^{1}$ (I)
}

Received: 8 September 2020 / Accepted: 22 September 2020 / Published online: 15 October 2020

(c) The Author(s) 2020

\begin{abstract}
In plant pest diagnosis, Sanger sequencing of marker genes (DNA-barcoding) is the most applied and appropriate method for the identification of insects. Standard PM7/129 of the European and Mediterranean Plant Protection Organization (EPPO) includes a number of primers and PCR protocols for diagnosing insect pests. LCO1490 and HCO2198 primers recommended herein were shown to be excellent tools for amplifying a fragment of the COI gene from a vast range of arthropods. The $\mathrm{COI}$ barcoding region is available for thousands of arthropod taxa in public databases and ready-to-use for evolutionary studies. However, we found that LCO1490 and HCO2198 primers are not working for bark beetles of genus Ips. The attempt to amplify this gene fragment from an individual organism using the barcoding primers led to DNA amplification of associated wasps and nematodes, which were apparently vectored by the beetle. Thus, new primers for Ips that bind specifically to another (non-barcoding) region of the $\mathrm{COI}$ gene were developed in the past years. These primers were successfully applied in phylogenetic analyses of this genus, resulting in the adverse effect that $C O I$-based Ips phylogenies cannot be expanded to higher systematic categories without sequencing the outgroups (as they are not available in databases yet). Here we provide new primers for Ips that differ significantly from DNA sequences of Ips-associated wasps and nematodes and bind to a COI fragment that largely overlaps with the barcoding region proposed in the EPPO standard. Furthermore, using these primers we developed a quick PCR-based test for detecting Ips duplicatus, a quarantine pest currently emerging in many European countries.
\end{abstract}

Keywords Ips duplicatus · DNA-barcoding $\cdot$ Primer design $\cdot$ Molecular diagnosis $\cdot$ Insect pests

\section{Introduction}

The suitability of the mitochondrial gene encoding subunit I of Cytochrome oxidase (COI, CO1 or COX1) as a molecular marker for evolutionary studies of a wide range of organisms (particularly animals) was already shown more than

\section{Electronic supplementary material The online version of this} article (https://doi.org/10.1007/s41348-020-00388-w) contains supplementary material, which is available to authorized users.

Matthias Becker

matthias.becker@julius-kuehn.de

Björn Hoppe

bjoern.hoppe@julius-kuehn.de

1 Julius Kühn-Institut, Institute for National and International Plant Health, Messeweg 11/12, 38104 Braunschweig, Germany two decades ago (Simon et al. 1994, Lunt et al. 1996). Since then many PCR primers have been designed for more or less conserved regions of the gene in order to enable identification and phylogenetic analyses of diverse species across eukaryotes (often called "DNA barcoding"). The European and Mediterranean Plant Protection Organization (EPPO) diagnosis standard PM7/129 (1) recommends DNA barcoding of the COI gene using primers LCO1490 and HCO2198 for PCR and subsequent sequencing of the DNA fragment (EPPO 2016). These universal primers were shown to amplify a 710-bp COI fragment from a broad range of metazoan invertebrates (709-bp fragment in many arthropods) (Folmer et al. 1994). In addition, the EPPO Standard further provides two PCR-alternatives amplifying a COI-fragment of $745 \mathrm{bp}$ using cocktails of degenerative primer. Among insects these primers (here: LCO1490 and HCO2198) were shown to cover species of Cerambycidae and Curculionidae (both Coleoptera), Agromyzidae and Tephritidae (both 
Diptera), Noctuidae (Lepidoptera) and Thripidae (Thysanoptera) (compare Table 1 of the EPPO Standard). In addition, during a test performance study conducted in the frame of "EUPHRESCO DNA Barcoding-Optimizing and validating DNA barcoding protocols for plant pests" (led by Dutch NPPO) another 90 arthropod genera comprising 32 families within Coleoptera (3), Diptera (6), Hemiptera (3), Hymenoptera (6), Lepidoptera (13) and Thysanoptera (1) were successfully tested using the suggested primer combinations and PCR-settings.

The double-spined spruce bark beetle Ips duplicatus (Sahlberg 1836) (Coleoptera: Curculionidae, Scolytinae) is native to Europe and has been reported from $15 \mathrm{EU}-$ member states. Its distribution range covers mainly Eastern European countries and Scandinavia, but also Asian parts of Russia (EFSA 2017). According to Zimová et al. (2019), the beetle is currently spreading to Norway spruce (Picea abies) in many European parts, with high outbreak potentials especially where drought events and warm temperatures coincide with Picea abies outside its native range. In that sense, climate change may also lead to an increasing number of I. duplicatus generations per year (Holusa et al. 2003). The threat that I. duplicatus poses to European forests is controversial. Since I. duplicatus is supposed to be a secondary pest that follows and coincides with other bark beetles, some scientists consider it to have low detrimental effect. On the opposite, the beetle is considered to be the most important harmful biotic agent on Norway spruce in Czech Moravia and Polish Silesia (Zahradník and Zahradníková 2019). Reported mass propagations of bark beetles in Czech Republic since 2015 (Knížek and Liška 2019) (mainly Ips typographus and I. duplicatus) have aroused interest in further investigations on the current distribution of the rather "unknown" Nordic member of the genus Ips in neighboring countries (e.g., Steyerer 2019). However, the species is listed in Annex III of Commission implementing Regulation (EU) 2019/2072 with existing protective zones in Greece, Ireland and the UK. Reliable information on its distribution in Germany was lacking before 2019. Petercord and Lemme (2019) refer to early reports of Ips duplicatus in Bavaria from the 1920s and 1950s, but mass propagations, as known from other bark beetles, were not observed. Responsible Plant protection services in the Federal states were tasked to provide monitoring data for Ips duplicatus starting in spring 2019.

Beetles collected in 2019 from insect traps (slit traps with "Dupliwit" as lure; available at Witasek, Feldkirchen, Austria) in four German federal states were morphologically diagnosed as I. duplicatus (personal communication with German plant protection services) and reference material was sent to Julius Kühn-Institut (Forest Quarantine Laboratory as part of German National Reference Laboratory) for molecular diagnosis/ confirmation. As an outcome of the monitoring, Ips duplicatus was later officially reported and confirmed from, e.g., across Bavaria (Lemme et al. 2020) and Baden-Württemberg (John et al. 2020). Irrespective of the still undetermined threat to German forestry the extensive monitoring of I. duplicatus, which has only started recently, will require a molecular tool for easy and rapid detection of I. duplicatus and its differentiation from widely distributed I. typographus. Such a tool will also be of interest to other countries such as Switzerland, where I. duplicatus was introduced lately (Lässig 2019).

We successfully applied the EPPO PM 7/129 (1) for diagnosing diverse insect genera such as Agrilus, Anoplophora, Aromia, Componotus, Pityogenes, Tetropium and Xyela. However, when following the protocol for diagnosing two species of bark beetles (Ips duplicatus and Ips typographus), we received surprising sequencing results. However, what proved to be an appropriate tool for molecular diagnosis of a range of regulated insect pests, turned out to be unsuitable for bark beetles of the genus Ips (family Curculionidae, subfamily Scolytinae). This inapplicability was experienced during monitoring campaigns against Ips duplicatus in Germany in early 2019. DNA-barcoding of collected species (morphologically preidentified according to Steyer et al. 2019) following the EPPO PM 7/129 Standard resulted in high-quality non-target DNA sequences. It is well documented that all species of genus Ips are associated with nematodes (Susoy and Herrmann 2014), but to the best of our knowledge, it was overlooked that the COI barcoding primers LCO1490 and HCO2198 bind much better to DNA of nematodes of the genus Micoletzkya than to DNA of bark beetles (Supplemental Fig. 1). Most species of the genus Micoletzkya are host species specific, but hosting the identical nematode (Micoletzkya buetschlii) Ips duplicatus and Ips typographus are among the rare exceptions from this rule (Fig. 2, adopted from Susoy and Herrmann 2014). Braasch et al. 1999 alone reported 18 scolytid species (four species within the genus Ips) to be associated with wood-inhabiting nematodes. In addition, the fact that Ips typographus is often infested by parasitic wasps of the genus Ropalophorus (Wegensteiner et al. 2017) renders diagnosis of Ips duplicatus and I. typographus even more challenging and may provide additional false positive results.

Here we show why the EPPO standard protocol for diagnosing arthropods using LCO1490 and HCO2198 barcoding primers is in its current version not suitable for diagnosing Ips duplicatus und I. typographus and recommend our newly developed and successfully tested primer pairs for rapid diagnosis of these bark beetles. 


\section{Material and methods}

\section{DNA extraction, PCR and sequencing (standard procedures according to PM7/129)}

During initial processing of ten insect samples that were received from extensive monitoring campaigns in Germany, protocols as recommended in the EPPO PM7/129 Standard (EPPO 2016) were applied. Briefly, total DNA from individual adult species was extracted, using the Blood \& Tissue Kit (Qiagen, Hilden, Germany) according to manufacturer instructions. Spectrophotometry of genomic template DNA using a NanoDrop ND-8000 (ThermoFisher Scientific, Dreieich, Germany) proved consistent DNA concentrations in the extracts. PCR-settings to amplify $709 \mathrm{bp}$ of the mitochondrial cytochrome $c$ oxidase subunit I (COI) gene of arthropods was adapted from Folmer et al. (1994) using the primer combination LCO1490: 5'-GGTCAACAAATCATAAAGATATTGG-3' and HCO2198: 5'-TAAACTTCAGGGTGACCAAAAAAT CA-3'. PCR Mastermix using the Bio-X-ACT Shortmix (Bioline, London, UK) was prepared according to the EPPO Standard. PCR amplification was performed using the proposed PCR program with an initial denaturation at $94{ }^{\circ} \mathrm{C}$ for $3 \mathrm{~min}$, followed by 5 cycles of denaturation at $94{ }^{\circ} \mathrm{C}$ for $30 \mathrm{~s}$, annealing at $45^{\circ} \mathrm{C}$ for $30 \mathrm{~s}$, and extension at $72{ }^{\circ} \mathrm{C}$ for $1 \mathrm{~min}$, followed by 35 cycles of $94{ }^{\circ} \mathrm{C}$ for $30 \mathrm{~s}, 51{ }^{\circ} \mathrm{C}$ for $1 \mathrm{~min}$ and $72{ }^{\circ} \mathrm{C}$ for $1 \mathrm{~min}$, with a final 10 min extension step at $72{ }^{\circ} \mathrm{C}$. To check for successful DNA amplification, the PCR products than were separated on a $1.5 \%$ agarose gel.

New Primer design and adjusted PCR-settings.

Geneious Prime (Biomatters Ltd) software was used for gene sequence comparison. Primers were designed generating a $C O I$ gene sequence alignment of Ips duplicatus, I. typographus, other bark beetles as well as associated bark beetle symbionts (Micoletzkya spp.) and parasites (Ropalophorus clavicornis) searching for primer binding sites with a maximum number of nucleotide mismatches between Ips on the one hand and symbionts and parasites on the other. Several primers and primer combinations were tested regarding specificity and reproducibility, of which the following three primers turned out to be the best:

dupl_F_spec: 5'-CTTCCCCCCTCTCTAGCCC-3', Ips_F_cons: 5'-CAAATATTGCCCATGAAGGAAC-3'. Ips_R_cons: 5'-GCATCTGGATAATCTGAGTAACGT CG-3'.

These primers were used in the following pairs amplifying a $C O I$ gene fragment of the given size: dupl_F_spec x Ips_R_cons $=1024$ bp, Ips_F_cons x Ips_R_cons $=936$ bp.
For PCR, a $25 \mu \mathrm{l}$ reaction mix was set up as follows: $12.5 \mu \mathrm{l}$ MyFi Mix (Bioline) polymerase mix (2x), $9.5 \mu \mathrm{l}$ water, $0.5 \mu \mathrm{l}$ primer $\mathrm{F}, 0.5 \mu \mathrm{l}$ primer $\mathrm{R}, 2 \mu \mathrm{l}$ template (genomic DNA). A BIO-RAD T100 thermal cycler was used for PCR. The thermocycler profile was as follows: step 1: 3 min at $95{ }^{\circ} \mathrm{C}$, step 2 ( 35 cycles): $30 \mathrm{~s}$ at $95{ }^{\circ} \mathrm{C}$, $30 \mathrm{~s}$ at $55^{\circ} \mathrm{C}, 1 \mathrm{~min}$ at $72{ }^{\circ} \mathrm{C}$, step 3: 5 min at $72{ }^{\circ} \mathrm{C}$. An $1 \%$ agarose gel was poured, and loaded samples were run for $30 \mathrm{~min}$ at $80 \mathrm{~V}$. Roti-GelStain from ROTH (Carl Roth, Karlsruhe, Germany) was used for visualization of DNA bands in a BIO View transilluminator from biostep. PCRDNA was purified using the innuPREP PCRpure kit from Analytik Jena (Analytik Jena, Jena, Germany), and a volume of $10 \mu \mathrm{l}$ was sent to Macrogen Europe for sequencing following the company's instructions.

\section{Results}

When following the EPPO PM7/129 standard barcoding protocol for diagnosing two species of bark beetles (Ips duplicatus and Ips typographus), we received surprising sequencing results. The DNA chromatograms were of high quality (Supplemental Fig. 2), but nucleotide BLAST against NCBI GenBank revealed $>99 \%$ identity to either a symbiotic nematode (Micoletzkya buetschlii) or a parasitic wasp (Ropalophorus clavicornis) (Fig. 1c) indicating that not DNA of Ips was successfully amplified but "non-target" DNA of vectored nematodes and wasps, respectively. The reason for these false positive results is the low complementarity between primers LCO1490/HCO2198 and primer binding sites in Ips (Fig. 1d). As barcoding primers are always designed for highly conserved DNA regions, it is possible that DNA of an organism associated with the target organism matches the primer sequences significantly better than the target DNA does. In such a case, running a PCR will result in DNA amplification of the associated organism. To the best of our knowledge, this was not reported earlier for the genus Ips, but other researchers must have encountered this problem before as they designed new primers for Sanger sequencing that bind outside the $\mathrm{COI}$ barcoding region (Fig. 1a).

To continue diagnosis of Ips duplicatus and differentiation from I. typographus by simple PCR (without sequencing), we designed two new primer pairs. Prior, additional literature and database surveys were conducted to identify available primers for the identification of European bark beetles based on sequencing of the COI Region. Two Ips specific primers, Dick/Pat and AC1-J-2183/AC1-N-2611 (compare discussion section), were identified to amplify two fragments of the $\mathrm{COI}$ marker gene, but were not overlapping with the fragment amplified by the Barcoding primer LCO1490/HCO2198 proposed by EPPO. Hence, we designed three primers to be combined in two different PCRs 


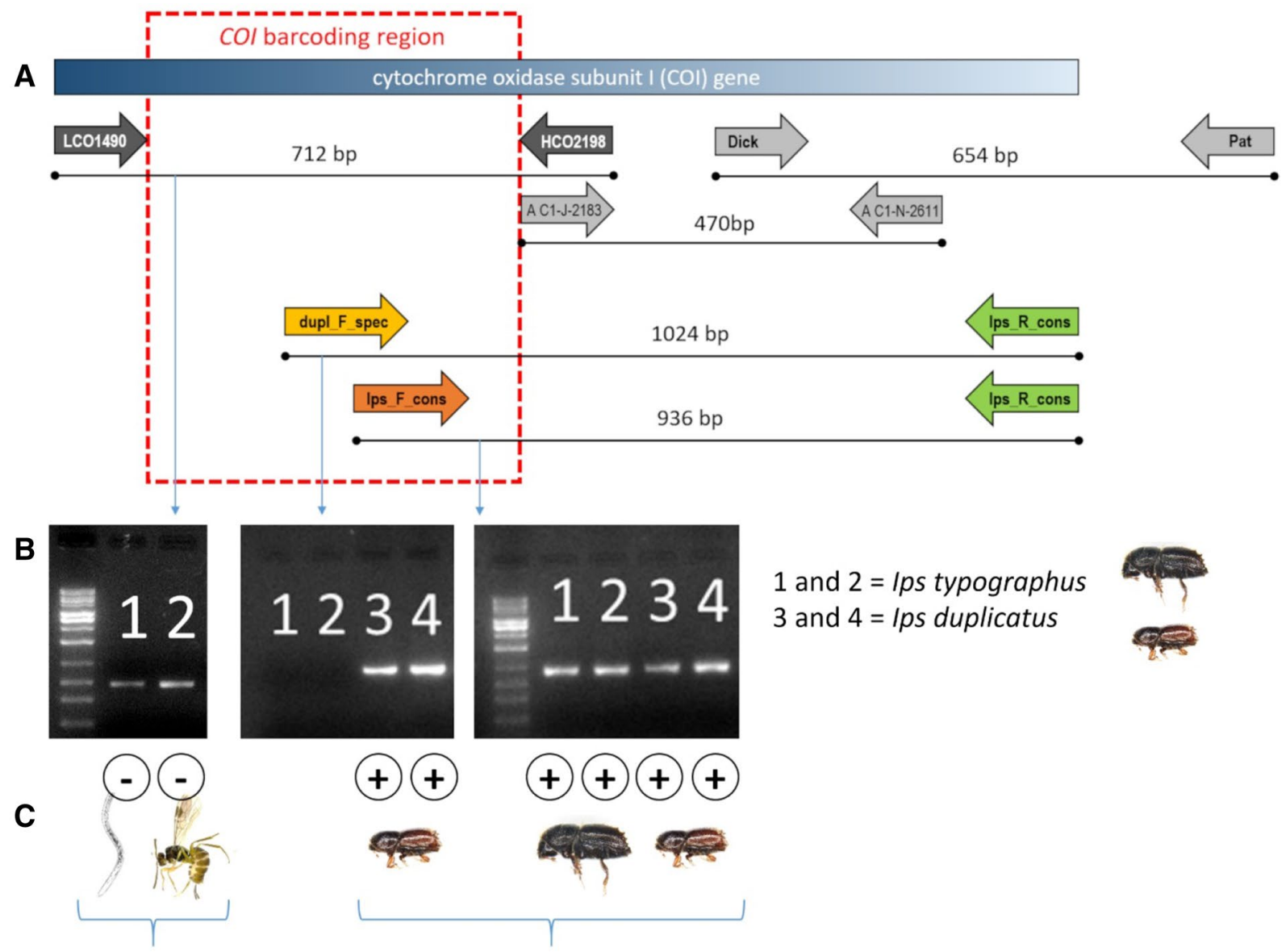

symbionts/parasites

bark beetles
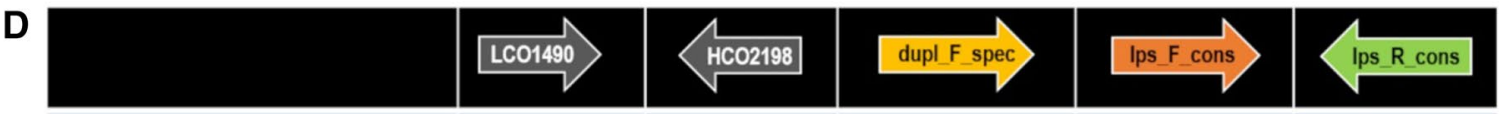

Ips duplicatus
Ips typographus

$*$

3

0

0

0

Pityogenes chalcographus

12

4

5-6

1

0

Micoletzkya buetschlii

$*$

5

$8-10$

1-2

2-3

Ropalophorus clavicornis

$*$

2

12

11

10

$*$

8

*

*unknown number of SNPs in primer binding sites (since none of sequences deposited to databases covers this region); the Ropalophorus clavicornis image in C was taken from BOLDSYSTEMS

Fig. 1 a COI gene and five primer pairs: barcoding primers LCO1490/HCO2198, Ips specific primers Dick/Pat and AC1-J-2183/ AC1-N-2611 and our two new primer pairs. Note that regions amplified by Dick/Pat and AC1-J-2183/AC1-N-2611 do not overlap with the COI barcoding region-except primer binding sites!, b DNA amplified in PCR using primers LCO1490/ HCO2198 (left) and our

in order to fulfill both criteria: specific binding to DNA template and covering at least a fraction of the standard barcoding region.

The reverse primer is the same in both primer pairs and binds to a conserved DNA region of both Ips species as well as other bark beetles (primer "Ips_R_cons", Fig. 1a). The new primer pairs, specific to I. duplicatus (middle) as well as specific to genus Ips (right) (Dick/Pat and AC1-J-2183/AC1-N-2611 primers were not employed in PCR), $\mathbf{c}$ photographs of the sequenced organisms, $\mathbf{d}$ number of nucleotide mismatches (SNPs) between primers and primer binding sites. Note that Micoletzkya buetschlii is a nematode and Ropalophorus clavicornis a wasp

forward primers differ significantly: one of them binds specifically to I. duplicatus (primer "dupl_F_spec"), while the other one binds to both species and further bark beetles of genus Ips (primer "Ips_F_cons"). Using both primer pairs in parallel (in two different PCRs), one can determine (even in the co-occurrence of nematodes or parasitic wasps) whether 
the organism is (i) I. duplicatus $=$ a band in $1 \mathrm{st}$ PCR and a band in 2nd PCR, (ii) not I. duplicatus but another bark beetle $=\mathrm{a}$ band in 2nd PCR only or (iii) no bark beetle at all $=$ no bands (Fig. 1b). The annealing temperature in the thermocycler profile is $55^{\circ} \mathrm{C}$ (and as such it is below the Tm of the primers) and enables binding of primers to primer binding sites in the COI gene with up to three nucleotide mismatches (as determined experimentally). Therefore, using primer "Ips_F_cons x Ips_R_cons" DNA fragments of a range of bark beetles can be amplified and thereafter sequenced for confirmative diagnosis. For instance, we obtained only a band in the 2nd PCR but not in the 1st PCR in several samples from infested trees from Thuringia (Supplemental Fig. 3) suggesting another bark beetle than Ips duplicatus and diagnosed Pityogenes chalcographus by sequencing. In contrast, amplification of nematode and wasp DNA having 10 and 11 nucleotide mismatches to primer "Ips_F_cons", respectively, (Fig. 1d) can be excluded.

Figure 2 provides an overview of the decision steps in which primer pairs from EPPO protocol PM 7/129 and the new protocol presented in this article can be used for efficient diagnosis of bark beetles. Depending on the kind of suspicion (e.g. via prior morphological analysis), the researcher may start with one of the three primer pairs shown in Fig. 2.

\section{Discussion}

Blasting the nucleotide sequences of barcoding primers LCO1490 and HCO2198 (EPPO PM 7/129 (1) adapted from Folmer et al. 1994) to GenBank databases showed that these primers are suitable for diagnosing diverse organisms. Focussing on best hits with $100 \%$ identity BLASTn searches (date: 12th July 2020) yielded 81 organisms for primer HCO2198, among them arthropods, molluscan and rotifers. Regarding primer LCO1490 BLASTn search yielded more than a thousand best hits including diatoms, sponges, worms and also vertebrates and even plants. The primers were designed by Folmer and colleagues for amplification of the mitochondrial Cytochrome $\mathrm{C}$ oxidase subunit I gene from diverse metazoan invertebrates (Folmer et al. 1994) and were repeatedly shown to allow phylogenetic analyses across eukaryotes.

However, the benefit of this universal applicability of the primers turned out to be a disadvantage while sequencing inadvertently mixed DNA samples consisting of target organism and associated symbionts or parasites. Organisms from different phyla live frequently together in complex interactions and may be that closely attached to each other that the target organism cannot be physically isolated from the matrix. This may lead to false positive results if complementarity between primer sequences and primer binding sites of associated organisms is higher than between primer sequences and primer binding sites of the target organism. The fact that not a single Ips duplicatus sequence from the barcoding region is deposited in GenBank, Bold Systems nor Q-Bank suggests that other researchers may have encountered error-proneness of primer pair LCO1490/ HCO2198 before.

The EPPO PM 7/129 standard proposes two alternative PCR approaches to amplify a $745 \mathrm{bp}$ fragment of the $\mathrm{COI}$ gene, each using a cocktail of five degenerated COI primers. The degenerated primers themselves consist of up to 36 specific primers yielding a mixture of $>40$ specific primers per cocktail. Applying cocktails of degenerated primers and using initial PCR cycles with an annealing temperature of $45^{\circ} \mathrm{C}$ might help to amplify DNA from organisms with very low primer matches, but is certainly not the method of choice for amplifying specific target DNA from a mixed DNA sample and should not be recommended for barcoding approaches as part of reference diagnostics. In compliance with this, the authors of PM 7/129 declared that the selectivity criterion does not apply to the primer cocktails as individual specimens are used.

Primer pairs other than LCO1490/HCO2198 (Folmer et al. 1994) such as "Dick/Pat" (Lunt et al 1996) were designed for partial amplification of the COI gene and were successfully applied for genetic comparison of different Ips duplicatus populations (Lakatos et al. 2007). However, primers "Dick/Pat" bind outside the LCO1490/HCO2198 region yielding a DNA fragment not overlapping with the typical COI barcoding fragment. Consequently, it is impossible to perform phylogenetic analyses on organisms of which some were sequenced using LCO1490/HCO2198 and others using Dick/Pat primers. The DNA fragments amplified by our primer pairs overlap significantly with the $C O I$ barcoding fragment: $331 \mathrm{bp}$ using the conserved primer "Ips_F_cons" and 419 bp using the I. duplicatus-specific primer "dupl_F_ spec". Apart from enabling phylogenetic analyses, another advantage of covering a part of the barcoding region is that similarity of a primer and the primer binding site of any nematode presumably associated with Ips spp. can easily be determined by in silico analysis.

Stauffer et al. 1997 used primers described by Juan et al. 1995 and developed by Lunt et al. 1996 in order to perform phylogenetic analyses on seven European Ips species among them Ips typographus and I. duplicatus. However, again a $\mathrm{COI}$ fragment not overlapping with the $\mathrm{COI}$ barcoding fragment was used. Cognato and Sperling (2000) performed a comprehensive phylogenetic study on genus Ips using modified versions of the Dick/Pat primers and extending the sequenced DNA fragment while employing another primer pair: AC1-J-2183/AC1-N-2611 (Fig. 1a). Surprisingly, Cognato and Sperling decided to put the forward primer at the position of $\mathrm{HCO} 2198$, the reverse barcoding primer. The reason might have been the lack of information about the 


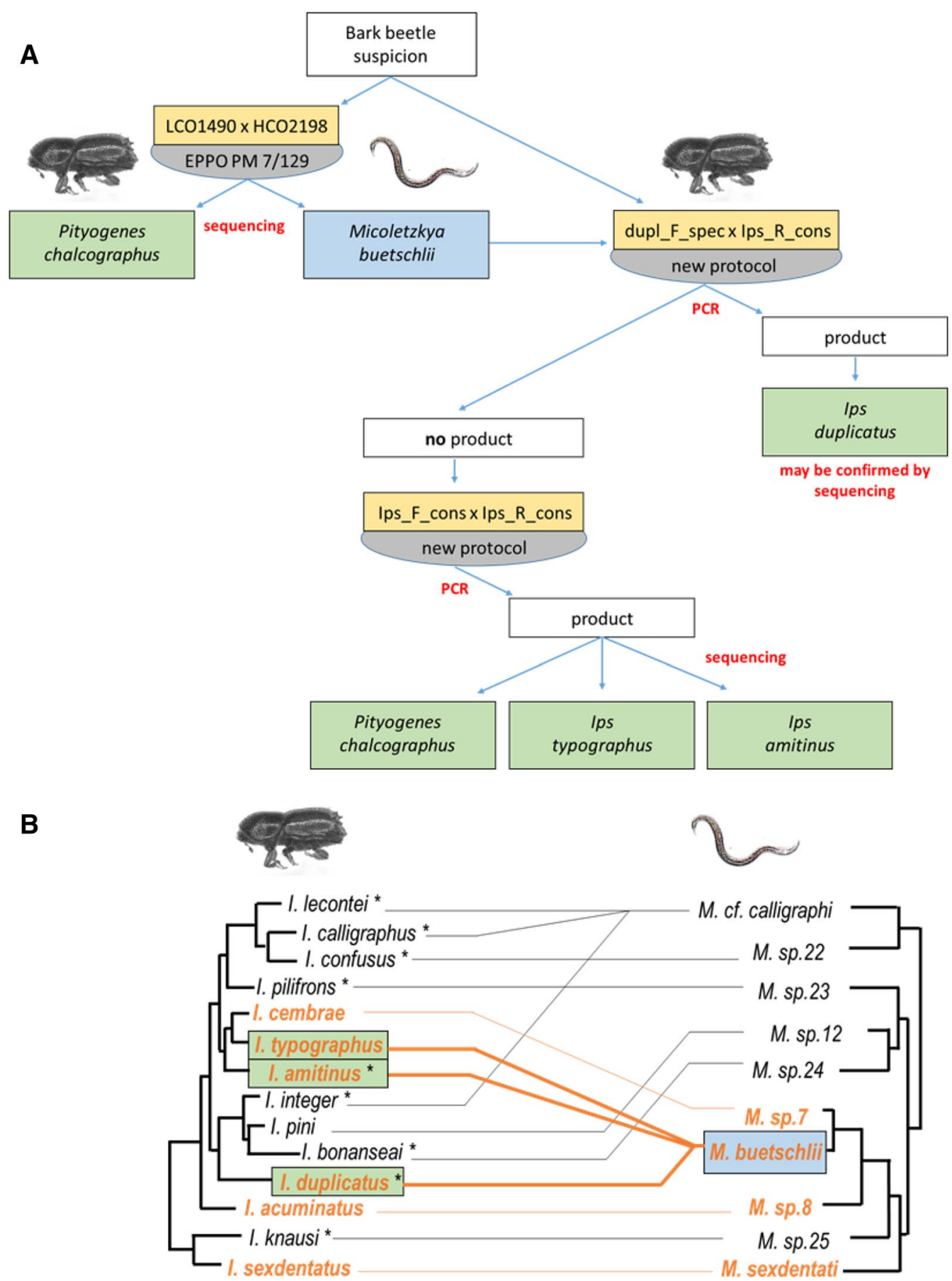

Fig. 2 a Schematic flow diagram of primers used for diagnosing particular bark beetles and expected outcome for different species, $\mathbf{b}$ phylogenetic relationships of bark beetles of genus Ips and associated nematodes of the Micoletzkya buetschlii crown group, adopted from Susoy and Herrmann 2014; the three other Micoletzkya crown groups are not shown; orange color refers to taxa from Europe and black color to taxa from America. Incongruency of Ips and Micoletzkya phylogenies indicates (i) that lineage-specific evolution of both organ- isms may switch from co-evolution to "host insect transition" when different bark beetles infest the same host tree and (ii) that both species, Ips duplicatus and I. typographus, host Micoletzkya buetschlii (as confirmed by us sequencing both species with EPPO barcoding primers LCO1490/ HCO2198). Asterisks indicate taxa for which the COI barcoding region has not been sequenced yet (no data deposited at GenBank) 
Ips barcoding sequence. The development of alternative primers led to an interesting appearance of the investigated COI gene sequence of genus Ips: the gene fragment outside the barcoding region is well known, but the sequence of the barcoding region itself is still missing for most species (Supplementary Fig. 4).

Susoy and Herrmann (2014) published an impressive study about the co-evolution of bark beetles (genus Ips) and nematodes (genus Micoletzkya) illustrated by phylogenies based on multiple genes (see also Fig. $2 b$ in this article). Meaningfully, the authors sequenced $\mathrm{COI}$ of the nematodes but not $C O I$ of the beetle species.

Metabarcoding approaches using a combination of several primer pairs and high throughput sequencing (HTS) circumvent the dilemma of false positive results by concatenating DNA sequences of several different barcoding genes, allowing for a more reliable diagnosis of critical taxa (even in the presence of a wrong $C O I$ gene sequence). This procedure has been applied successfully to bark beetles and provides satisfying results even while using primers LCO1490 and HCO2198 (Morinière et al. 2016). However, HTS is expensive compared to conventional PCR and Sanger sequencing, particularly if only a single suspicious case has to be evaluated. Furthermore, any false positive result included in metabarcoding analysis weakens significance and robustness of the diagnosis.

Using a combination of three primers, we here provide a simple and convenient approach for diagnosing and distinguishing Ips typographus, a pest native to Germany, from Ips typographus, a quarantine pest potentially newly introduced or re-introduced to Germany. Furthermore, we offer a primer pair to the scientific community that allows the inclusion of genus Ips into phylogenetic analyses of diverse arthropods.

\section{Outlook}

The observed physical interaction between bark beetles of the genus Ips and nematodes of the genus Micoletzkya is certainly only one of many examples exhibiting difficulties to specifically amplify and sequence DNA of a target organism from a mixed (often environmental) DNA sample using barcoding primers. On the other hand, barcoding primers proved to be advantageous for phylogenetic analyses and are required for many evolutionary studies. Several scenarios predict an increased number of introduced pests due to climate change and global trade in the future (e.g., Roques 2010). In order to respond appropriately to this threat, it is important to develop highly specific protocols for diagnosing newly introduced pests. An automated procedure such as a bioinformatics pipeline for designing specific primers under consideration of all known information (not only DNA sequences but also metadata about, e.g., associated organisms) would be helpful to simplify future diagnostics of any given or newly emerging pest.

Acknowledgements Hannes Lemme is thanked for providing reference material of Ips duplicatus.

Author contributions $\mathrm{MB}$ and $\mathrm{BH}$ performed laboratory work and data analysis. All authors drafted the manuscript.

Funding Open Access funding enabled and organized by Projekt DEAL. The current study could be realized via funding of the FNRProject "ANOPLO-diag" (Fachagentur Nachwachsende Rohstoffe) (Förderkennzeichen: 22010316).

\section{Compliance with ethical standards}

Conflicts of interest The authors declare that they have no conflict of interest.

Open Access This article is licensed under a Creative Commons Attribution 4.0 International License, which permits use, sharing, adaptation, distribution and reproduction in any medium or format, as long as you give appropriate credit to the original author(s) and the source, provide a link to the Creative Commons licence, and indicate if changes were made. The images or other third party material in this article are included in the article's Creative Commons licence, unless indicated otherwise in a credit line to the material. If material is not included in the article's Creative Commons licence and your intended use is not permitted by statutory regulation or exceeds the permitted use, you will need to obtain permission directly from the copyright holder. To view a copy of this licence, visit http://creativecommons.org/licenses/by/4.0/.

\section{References}

Braasch H, Metge K, Burgermeister W (1999) Bursaphelenchus species (Nematoda, Parasitaphelenchidae) found in coniferous trees in Germany and their ITS-RFLP patterns. Nachrichtenblatt des Deutschen Pflanzenschutzdienstes 51(12):312-320

Cognato AI, Sperling FA (2000) Phylogeny of Ips DeGeer species (Coleoptera: Scolytidae) inferred from mitochondrial cytochrome oxidase I DNA sequence. Mol Phylogenet Evol 14(3):445-460

Jeger M, Bragard C, Caffier D, Candresse T et al, EFSA Panel on Plant Health (PLH) (2017) Pest categorisation of Ips duplicatus. EFSA J 15(10):e05040

EPPO (2016) PM 7/129 (1) DNA barcoding as an identification tool for a number of regulated pests. EPPO Bull 46:501-537

Folmer O, Black M, Hoeh W, Lutz R, Vrijenhoek R (1994) DNA primers for amplification of mitochondrial cytochrome $\mathrm{c}$ oxidase subunit I from diverse metazoan invertebrates. Mol Mar Biol Biotechnol 3(5):294-299

Holuša J, Zahradník P, Knížek M \& Drápela K (2003) Seasonal flight activity of the double-spined spruce bark beetle Ips duplicatus (Coleoptera, Curculionidae, Scolytinae) in Silesia (Czech Republic). Biologia 58:935-941

John R, Stettner G, Delb H (2020) Nordischer Fichtenborkenkäfer jetzt auch in Baden-Württemberg nachgewiesen. FVA-Einblick 3/2020, S. 15-19. (https://www.waldwissen.net/wald/tiere/insekten_wirbe llose/fva_nordischer_fichtenborkenkaefer/index_DE; available 31 August 2020) 
Juan C, Oromi P, Hewitt GM (1995) Mitochondrial DNA phylogeny and sequential colonization of Canary Islands by darkling beetles of the genus Pimelia (Tenebrionidae). Proc R Soc Lond B Biol Sci 261(1361): 173-180

Knížek M, Liška J (2019) Borkenkäfer-Massenvermehrung in tschechischen Wäldern. LWF aktuell 120. https://www.lwf.bayern.de/ waldschutz/forstentomologie/213649/index.php

Lakatos F, Grodzki W, Zhang QH, Stauffer C (2007) Genetic comparison of Ips duplicatus (Sahlberg, 1836) (Coleoptera: Curculionidae, Scolytinae) populations from Europe and Asia. J For Res 12(5):345-349

Lässig (2019) Neue Borkenkäferart in der Schweiz. (https://www.wsl. $\mathrm{ch} /$ de/newsseiten/2019/11/neue-borkenkaeferart-in-der-schwe iz.html\#tabelement1-tab2; available 31 August 2020)

Lemme H, Sikora C, Petercord R, Hahn A (2020) Nordischer Fichtenborkenkäfer auch in Bayern weitverbreitet. (https://www.waldw issen.net/waldwirtschaft/schaden/insekten/lwf_nordischer_ficht enborkenkaefer/index_DE; available 31 August 2020)

Lunt DH, Zhang DX, Szymura JM, Hewltt OM (1996) The insect cytochrome oxidase I gene: evolutionary patterns and conserved primers for phylogenetic studies. J Insect Sci 5(3):153-165

Morinière J, de Araujo BC, Lam AW, Hausmann A, Balke M et al (2016) Species identification in malaise trap samples by DNA barcoding based on NGS technologies and a scoring matrix. PLoS ONE 11(5):e0155497. https://doi.org/10.1371/journal.pone.01554 97

Petercord R, Lemme H (2019) Der Nordische Fichtenborkenkäfer. LWF-aktuell 120. https://www.lwf.bayern.de/waldschutz/monit oring/211872/index.php

Roques A (2010) Alien forest insects in a warmer world and a globalised economy: impacts of changes in trade, tourism and climate on forest biosecurity. N Z J For Sci (Suppl) 40:77-94
Simon C, Frati F, Beckenbach A, Crespi B, Liu H, Flook P (1994) Evolution, weighting, and phylogenetic utility of mitochondrial gene sequences and a compilation of conserved polymerase chain reaction primers. Ann Entomol Soc Am 87(6):651-701

Stauffer C, Lakatos F, Hewitt GM (1997) The phylogenetic relationships of seven European Ips (Scolytidae, Ipinae) species. Insect Mol Biol 6(3):233-240

Steyrer G (2019) Wie weit verbreitet ist der Nordische Fichtenborkenkäfer (Ips duplicatus) in Österreich? Forstschz Aktuell 65:4

Susoy V, Herrmann M (2014) Preferential host switching and codivergence shaped radiation of bark beetle symbionts, nematodes of Micoletzkya (Nematoda: Diplogastridae). J Evol Biol 27(5):889-898

Wegensteiner R, Tkaczuk C, Kenis M, Papierok B (2017) Occurrence of Tomicobia seitneri (Hymenoptera: Pteromalidae) and Ropalophorus clavicornis (Hymenoptera: Braconidae) in Ips typographus adults (Coleoptera: Curculionidae: Scolytinae) from Austria. Pol Fr Biologia 72(7):807-813

Zimová S, Resnerová K, Vanická H, Horák J, Trombik J, Kacprzyk M, Holuša J (2019) Infection Levels of the Microsporidium Larssoniella duplicati in populations of the invasive bark beetle Ips Duplicatus: from native to new outbreak areas. Forests 10(2):131

Zahradník P, Zahradníková M (2019) Salvage felling in the Czech Republic's forests during the last twenty years. Cent Eur For J 65(1):12-20

Publisher's Note Springer Nature remains neutral with regard to jurisdictional claims in published maps and institutional affiliations. 